\title{
REALIZACJA PAKIETU ONKOLOGICZNEGO W POLSCE A DZIAŁALNOŚĆ PUBLICZNYCH INSTYTUTÓW I CENTRÓW ONKOLOGII
}

\section{REALIZATION OF A ONCOLOGY PACKAGE IN POLAND AND ACTIVITIES OF PUBLIC INSTITUTE AND CANCER CENTERS}

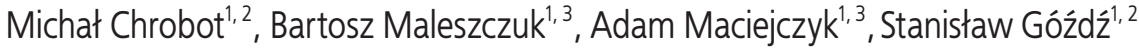 \\ 1 Ogólnopolskie Zrzeszenie Publicznych Centrów i Instytutów Onkologii, Wrocław \\ 2 Świętokrzyskie Centrum Onkologii w Kielcach \\ ${ }^{3}$ Dolnośląskie Centrum Onkologii we Wrocławiu
}

DOl: https://doi.org/10.20883/ppnoz.2019.15

\section{STRESZCZENIE}

Pakiet onkologiczny został wprowadzony w 2015 roku. W swoim założeniu miał poprawić dostępność do świadczeń diagnostyki i leczenia onkologicznego oraz jakość udzielanych świadczeń w całym kraju. Analizie poddano dane za okres 1.01.2015 - 30.04.2017, dotyczące świadczeń udzielonych w Polsce na rzecz pacjentów onkologicznych. Z przeprowadzonej analizy danych za okres 1.01.2015 - 30.04.2017 wynika, iż realizacja świadczeń z zakresu pakietu onkologicznego w Polsce opiera się na 19 placówkach, instytutach i publicznych centrach onkologii, skupionych wokół Ogólnopolskiego Zrzeszenia Publicznych Centrów i Instytutów Onkologii. Analizowane dane potwierdzają, że ponad 42\% świadczeń ambulatoryjnych oraz ponad 52\% świadczeń szpitalnych, jest udzielanych w placówkach zrzeszonych w stowarzyszeniu. Udział poszczególnych placówek w realizacji pakietu onkologicznego na terenie danego województwa waha się od 21\% do 89\% świadczeń udzielanych na rzecz pacjentów posiadających aktywną kartę diagnostyki i leczenia onkologicznego.

Słowa kluczowe: pakiet onkologiczny, szybkie leczenie onkologiczne, szybka diagnostyka onkologiczna, karta diagnostyki i leczenia onkologicznego, centrum onkologii.

\section{ABSTRACT}

The oncology package was introduced in 2015. In his assumption, he was to improve access to oncology diagnostics and treatment services as well as the quality of services provided throughout the country. Data for the period 01/01/2015 - 30/04/2017 regarding the services provided in Poland for oncological patients were given. The analysis of data for the period 01/01/2015 - 30/04/2017 shows that the implementation of services in the oncology package in Poland is based on 19 institutes and public centers of oncology, gathered around the National Association of Public Centers and Institutes of Oncology. The analyzed data confirms that over $42 \%$ of outpatient services and over $52 \%$ of hospital services are provided in associated institutions. The share of individual facilities in the implementation of the oncology package in a given province varies from $21 \%$ to $89 \%$ of the services provided to patients with an active diagnostic and oncological treatment card.

Keywords: oncological package, quick oncological treatment, quick oncological diagnostics, card of oncological diagnostics and treatment, cancer center.

\section{Podstawowe założenia pakietu onkologicznego w Polsce}

Pakiet onkologiczny to zbiór aktów prawnych, wprowadzających wytyczne dotyczące terminów, zakresu oraz sposobu wykonywania diagnostyki i leczenia onkologicznego w Polsce. Główną zmianą jest ustawa z dnia 22 lipca 2014 r. o zmianie ustawy o świadczeniach opieki zdrowotnej finansowanych ze środków publicznych oraz niektórych innych ustaw [1, 2], która stanowiła podstawę do wydania przez Ministra Zdrowia (MZ) aktów w randze rozporządzeń [3-9], a przez Prezesa Narodowego Funduszu Zdrowia (NFZ) - dokumentów w formie zarządzeń [10-16].

Pakiet onkologiczny miał skrócić czas prowadzenia diagnostyki i poprawić dostępność do leczenia onkologiczne- go dla pacjentów. Diagnostyka podejrzenia nowotworu w roku 2017 powinno trwać nie dłużej niż 7 tygodni (pierwotnie 9 tygodni w 2015 r. oraz 8 tygodni w 2016 r.), natomiast rozpoczęcie leczenia winno rozpocząć się $\mathrm{w}$ ciągu 14 dni od daty ustalenia planu leczenia [17].

Pacjent, u którego podejrzewany jest nowotwór złośliwy, powinien otrzymać kartę diagnostyki i leczenia onkologicznego (karta DiLO), która jest wydawana przez lekarza: oddziału szpitalnego, poradni specjalistycznej, a nawet lekarza podstawowej opieki zdrowotnej (POZ) [17]. Do jej wydania i dalszej obsługi wykorzystywany jest portal udostępniony przez NFZ [18]. Zakres danych oraz format karty DiLO określa wzór wskazany w rozporządzeniu MZ [7-9]. 
W myśl zapisów zarządzenia Prezesa NFZ szybka diagnostyka onkologiczna jest podzielona na etap wstępy (mający na celu potwierdzenie lub wykluczenie nowotworu złośliwego) i pogłębiony (mający na celu zróżnicowanie typu histopatologicznego nowotworu oraz ocenę stopnia zaawansowania choroby) $[10,11]$.

Po zakończonej diagnostyce, która potwierdziła nowotwór złośliwy, pacjent jest kierowany do etapu leczenia. Rozpoczyna się on od spotkania wielodyscyplinarnego zespołu terapeutycznego, który ustala indywidualny plan leczenia danego pacjenta. W konsylium (w zależności od lokalizacji i typu nowotworu) uczestniczą lekarze specjaliści:

- specjalności zabiegowej,

- onkologii klinicznej lub hematologii,

- radioterapii onkologicznej lub terapii izotopowej,

- oraz koordynator $[2,5,17]$.

Wykonanie świadczeń z zakresu diagnostyki i leczenia onkologicznego $w$ terminach ustawowych powoduje, iz płatnik publiczny finansuje wszystkie świadczenia bezlimitowo $[17,19]$.

\section{Realizacja pakietu onkologicznego w Polsce w okresie 1.01.2015 - 30.04.2017 a działalność placówek z Ogólnopolskiego Zrzeszenia Publicznych Centrów i Instytutów Onkologii}

94 W okresie od 1 stycznia 2015 r. do 30 kwietnia 2017 r. na terenie całego kraju wykonano świadczenia na rzecz 622227 pacjentów, na łączną wartość 3457010745,72 zł. Obie wartości rosną w trendzie czasu (liczba pacjentów o 25\%, a wartość świadczeń o 18\%). Więcej danych w tabelach 1 i 2.

Tabela 1. Liczba pacjentów, na rzecz których zrealizowano pakiet w okresie 1.01.2015 - 30.04.2017

\begin{tabular}{|l|c|c|c|}
\multicolumn{1}{|c|}{ Rodzaj } & 2015 & 2016 & 2017 \\
\cline { 1 - 1 } $\begin{array}{l}\text { Ambulatoryjne świadczenia } \\
\text { specjalistyczne }\end{array}$ & 75063 & 85557 & 33914 \\
$\begin{array}{l}\text { Leczenie szpitalne } \\
\text { Suma }\end{array}$ & 169151 & 190778 & 67764 \\
\hline 24214 & 276335 & 101678
\end{tabular}

Źródło: Dane otrzymane z Centrali Narodowego Funduszu Zdrowia.

Tabela 2. Wartość zrealizowanych świadczeń w ramach pakietu w okresie 01.01.2015 - 30.04.2017 (podano w zł)

\begin{tabular}{|c|c|c|c|}
\hline$\underbrace{\text { Rodzaj }}_{\text {rok }}$ & 2015 & 2016 & 2017 \\
\hline $\begin{array}{l}\text { Ambulatoryjne } \\
\text { świadczenia } \\
\text { specjalistyczne }\end{array}$ & 44996764,81 & 58971602,64 & 18919314,54 \\
\hline \multirow{2}{*}{$\begin{array}{l}\text { Leczenie } \\
\text { szpitalne } \\
\text { Suma }\end{array}$} & 1322667947,42 & 1491045817,86 & 520409298,46 \\
\hline & 1367664712,23 & 1550017420,50 & 539328613,00 \\
\hline
\end{tabular}

Źródło: Dane otrzymane z Centrali Narodowego Funduszu Zdrowia.
Świadczenia zostały zrealizowane w wielu zakresach, których liczba zmalała w ciągu analizowanego okresu - 927 podmiotów (o 30\%), szczególnie w rodzaju ambulatoryjna opieka specjalistyczna (spadek o 41\%). Szczegółowe dane w tabeli 3.

Tabela 3. Liczba zakresów, w których zrealizowano pakiet onkologiczny w okresie 1.01.2015 - 30.04.2017

\begin{tabular}{|l|c|c|c|}
\multicolumn{1}{|c|}{ Rodzaj/ } & 2015 & 2016 & 2017 \\
$\begin{array}{l}\text { Ambulatoryjne } \\
\begin{array}{l}\text { świadczenia } \\
\text { specjalistyczne }\end{array}\end{array}$ & 1866 & 1411 & 1103 \\
$\begin{array}{l}\text { Leczenie szpitalne } \\
\text { Suma }\end{array}$ & 1191 & 1121 & 1027 \\
\hline 057 & 2532 & 2130
\end{tabular}

Źródło: Dane otrzymane z Centrali Narodowego Funduszu Zdrowia.

Świadczenia w poszczególnych latach zostały zrealizowane w 848 placówkach w 2015 r., w 635 placówkach w 2016 r. oraz w 544 placówkach w 2017 r. Powyższe liczby uwzględniają także 19 podmiotów wchodzących w skład Ogólnopolskiego Zrzeszenia Publicznych Centrów i Instytutów Onkologii (OZPCilO) z terenu całego kraju (minimum 1 podmiot z terenu każdego województwa). Placówki te realizują świadczenia związane z pakietem onkologicznym w poszczególnych regionach. Szczegółowe dane $w$ tabeli 4 i na rycinie 1.

Tabela 4. Udział świadczeń szpitalnych związanych z realizacją pakietu onkologicznego wykonanych przez placówki Ogólnopolskiego Zrzeszenia Publicznych Centrów i Instytutów Onkologii w ogólne wartości świadczeń w okresie 1.01.2015 - 30.04.2017

\begin{tabular}{|l|c|c|c|}
$\begin{array}{l}\text { Wszystkie } \\
\text { szpitale }\end{array}$ & 2015 & 2016 & Symulacja 2017 \\
OZPCilO & 1322667947,42 zł & 1491045817,86 zł & 1561227895,38 zł \\
Udział w \% & 581816223,56 zł & 828706767,56 zł & 824572041,55 zł \\
\hline
\end{tabular}

Źródło: Dane otrzymane z Centrali Narodowego Funduszu Zdrowia.

Analizując dane dotyczące realizacji świadczeń w oddziałach szpitalnych przez placówki zrzeszone w OZPCilO, należy stwierdzić, iż niecały $1 \%$ placówek realizuje ponad połowę świadczeń związanych z diagnostyką i leczeniem onkologicznym na terenie kraju.

Analogiczny udział OZPCilO występuje w liczbie leczonych pacjentów w analizowanym okresie. Dane przedstawiono $w$ tabeli 5 i na rycinie 2. 


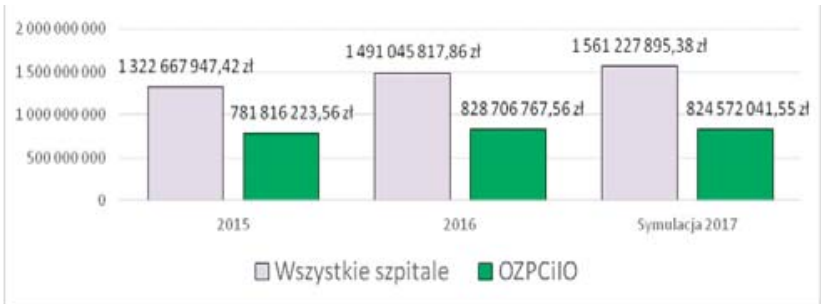

Rycina 1. Wartość wykonania pakietu onkologicznego w oddziałach szpitalnych placówek Ogólnopolskiego Zrzeszenia Publicznych Centrów i Instytutów Onkologii w ogólnej wartości świadczeń w okresie 1.01.2015 - 30.04.2017

Źródło: Dane otrzymane z Centrali Narodowego Funduszu Zdrowia.

Tabela 5. Udział liczby leczonych w oddziałach szpitalnych placówek Ogólnopolskiego Zrzeszenia Publicznych Centrów i Instytutów Onkologii w ogólnej liczbie pacjentów w pakiecie onkologicznym, w okresie 1.01.2015-30.04.2017

\begin{tabular}{|l|c|c|c|} 
& 2015 & 2016 & Symulacja 2017 \\
$\begin{array}{l}\text { Wszystkie } \\
\text { Szpitale }\end{array}$ & 169151 & 190778 & 203292 \\
OZPCilO & 93275 & 97385 & 99663 \\
Udział w \% & $55,1 \%$ & $51,0 \%$ & $49,0 \%$
\end{tabular}

Źródło: Dane otrzymane z Centrali Narodowego Funduszu Zdrowia.

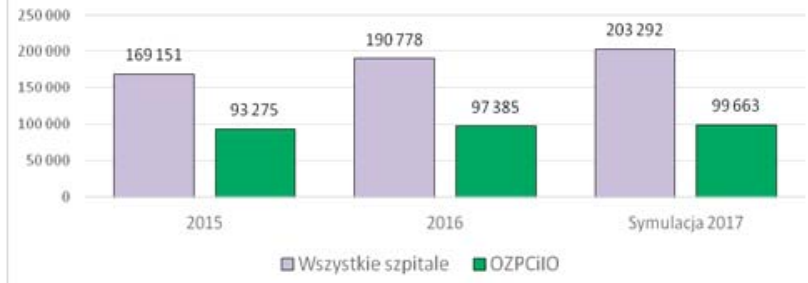

Rycina 2. Liczba pacjentów leczonych w oddziałach szpitalnych placówek Ogólnopolskiego Zrzeszenia Publicznych Centrów i Instytutów Onkologii w ogólnej liczby chorych, w okresie 1.01.2015 $-30.04 .2017$

Źródło: Dane otrzymane z Centrali Narodowego Funduszu Zdrowia.

Analogicznie zestawiono dane dotyczące diagnostyki onkologicznej wykonywanej w poradniach specjalistycznych. Poziom udziału OZPCilO w realizacji świadczeń w poszczególnych latach minimalnie maleje. Jednakże zarówno w zakresie wartości wykonywanych świadczeń, jak i liczby leczonych pacjentów przekracza ona $42 \%$ wszystkich pacjentów. Szczegółowe dane wskazano w tabelach 6 i 7 oraz na rycinach 3 i 4.
Tabela 6. Udział świadczeń ambulatoryjnych związanych z realizacją pakietu onkologicznego wykonanych przez placówki Ogólnopolskiego Zrzeszenia Publicznych Centrów i Instytutów Onkologii w ogólnej wartości świadczeń w okresie 1.01.2015 - 30.04.2017

\begin{tabular}{|l|c|c|c|} 
& 2015 & 2016 & Symulacja 2017 \\
$\begin{array}{l}\text { Wszystkie } \\
\text { szpitale }\end{array}$ & 44996764,81 zł & 58971602,64 zł & 56757943,62 zł \\
OzPCilO & 19636162,16 zł & 26150165,28 zł & 23992375,40 zł \\
Udział w \% & $43,6 \%$ & $44,3 \%$ & $42,3 \%$
\end{tabular}

Źródło: Dane otrzymane z Centrali Narodowego Funduszu Zdrowia.

Analizując dane dotyczące realizacji świadczeń w oddziałach szpitalnych przez placówki zrzeszone w OZPCilO, należy stwierdzić, iż realizują one ponad połowę świadczeń związanych z diagnostyką i leczeniem onkologicznym na terenie kraju.

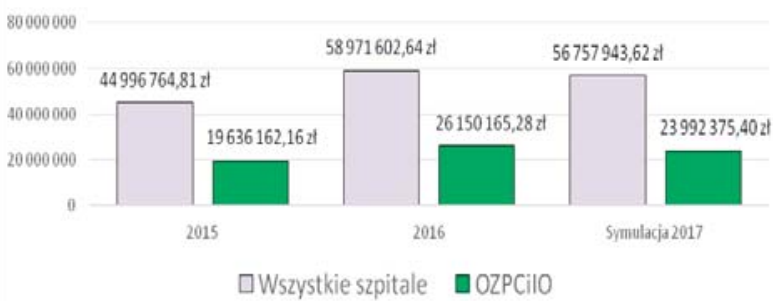

Rycina 3. Wartość wykonania pakietu onkologicznego w poradniach specjalistycznych placówek Ogólnopolskiego Zrzeszenia Publicznych Centrów i Instytutów Onkologii w ogólnej wartości świadczeń w okresie 1.01.2015 - 30.04.2017

Źródło: Dane otrzymane z Centrali Narodowego Funduszu Zdrowia.

Analogiczny udział OZPCilO występuje w liczbie leczonych pacjentów $w$ analizowanym okresie. Dane $w$ tabeli 5 i na rycinie 2

Tabela 7. Udział liczby leczonych w poradniach specjalistycznych placówek Ogólnopolskiego Zrzeszenia Publicznych Centrów i Instytutów Onkologii w ogólnej liczbie pacjentów w pakiecie onkologicznym, w okresie 1.01.2015 - 30.04.2017

\begin{tabular}{|l|c|c|c|} 
& 2015 & 2016 & Symulacja 2017 \\
Wszystkie szpitale & 75063 & 85557 & 101742 \\
OZPCilO & 35001 & 38341 & 43689 \\
Udział w \% & $46,6 \%$ & $44,8 \%$ & $42,9 \%$
\end{tabular}

Źródło: Dane otrzymane z Centrali Narodowego Funduszu Zdrowia. 


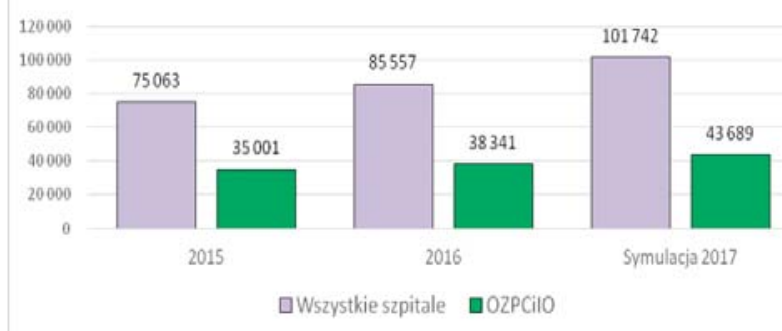

Rycina 4. Liczba pacjentów leczonych w poradniach specjalistycznych placówek Ogólnopolskiego Zrzeszenia Publicznych Centrów i Instytutów Onkologii w ogólnej liczby chorych, w okresie 1.01.2015 $-30.04 .2017$

Źródło: Dane otrzymane z Centrali Narodowego Funduszu Zdrowia.

Szczegółowe dane dotyczące realizacji pakietu onkologicznego przez członków OZPCilO w poszczególnych województwach w 2017 roku, w poszczególnych rodzajach świadczeń zawierają tabele 8 i 9.

Tabela 8. Wartość świadczeń i liczba leczonych w oddziałach szpitalnych placówek Ogólnopolskiego Zrzeszenia Publicznych Centrów i Instytutów Onkologii w poszczególnych województwach, w okresie 1.01.2017-30.04.2017

\begin{tabular}{|c|c|c|c|c|}
\hline $\begin{array}{l}\text { Ośrodek } \\
\text { OZPCilO }\end{array}$ & $\begin{array}{l}\text { Wartość } \\
\text { pakietu }\end{array}$ & $\begin{array}{c}\text { Liczba } \\
\text { pacjentów }\end{array}$ & $\begin{array}{l}\text { \% wartości w } \\
\text { województwie }\end{array}$ & $\begin{array}{c}\% \text { liczby } \\
\text { pacjentów w } \\
\text { województwie }\end{array}$ \\
\hline Wrocław & 23425211,68 & 2634 & 63,3 & 56,2 \\
\hline Bydgoszcz & 30785281,80 & 3680 & 75,5 & 68,3 \\
\hline Lublin & 17618286,40 & 2219 & 68,0 & 61,7 \\
\hline Zielona Góra & 2774431,00 & 434 & 53,8 & 47,9 \\
\hline tódź & 15778177,62 & 2110 & 46,7 & 47,7 \\
\hline Kraków & 9305556,00 & 1231 & 19,1 & 21,0 \\
\hline col Warszawa & 39099 480,16 & 4787 & 44,7 & 43,8 \\
\hline IGiChPW-wa & 2953028,00 & 157 & 3,4 & 1,4 \\
\hline Opole & 6697938,40 & 612 & 89,0 & 88,6 \\
\hline Brzozów & 5421460,21 & 738 & 35,7 & 31,6 \\
\hline Rzeszów & 6470038,64 & 1003 & 42,6 & 43,0 \\
\hline Białystok & 5606900,00 & 767 & 69,8 & 73,5 \\
\hline Gdańsk & 11652049,60 & 1208 & 43,8 & 35,8 \\
\hline Gdynia & 5633247,36 & 738 & 21,2 & 21,8 \\
\hline Gliwice & 34344754,08 & 4127 & 45,1 & 41,7 \\
\hline Kielce & 16894647,00 & 1944 & 90,1 & 82,9 \\
\hline Olsztyn & 8555680,64 & 1017 & 52,4 & 55,0 \\
\hline Poznań & 24146443,24 & 3044 & 50,2 & 44,2 \\
\hline Szczecin & 11066533,92 & 1271 & 44,7 & 35,6 \\
\hline RAZEM & 278229145,74 & 33721 & & \\
\hline
\end{tabular}

Źródło: Dane otrzymane z Centrali Narodowego Funduszu Zdrowia.
Udział poszczególnych placówek w realizacji w szpitalu pakietu onkologicznego w województwach jest różny, od 17,3\% w przypadku Centrum Onkologii w Krakowie do 90,4\% w przypadku Centrum Onkologii w Opolu (mediana dla wszystkich placówek w 2017 r. wynosi 46,7\%).

Tabela 9. Wartość świadczeń i liczba leczonych w poradniach specjalistycznych placówek Ogólnopolskiego Zrzeszenia Publicznych Centrówi Instytutów Onkologii w poszczególnych województwach, w okresie 1.01.2017-30.04.2017

\begin{tabular}{|c|c|c|c|c|}
\hline $\begin{array}{l}\text { Ośrodek } \\
\text { OZPCilO }\end{array}$ & $\begin{array}{l}\text { Wartość } \\
\text { pakietu } \\
(z \nmid)\end{array}$ & $\begin{array}{c}\text { Liczba } \\
\text { pacjentów }\end{array}$ & $\begin{array}{l}\text { \% wartości w } \\
\text { województwie }\end{array}$ & $\begin{array}{c}\text { \% liczby } \\
\text { pacjentów w } \\
\text { województwie }\end{array}$ \\
\hline Wrocław & 556860,36 & 852 & 36,5 & 28,5 \\
\hline Bydgoszcz & 1223405,88 & 2629 & 70,1 & 71,2 \\
\hline Lublin & 313320,31 & 503 & 46,4 & 46,5 \\
\hline Zielona Góra & 61469,65 & 86 & 33,5 & 31,3 \\
\hline Łódź & 299256,54 & 605 & 36,6 & 40,3 \\
\hline Kraków & 198267,42 & 350 & 14,5 & 12,5 \\
\hline COIWarszawa & 1585613,55 & 2390 & 48,9 & 44,5 \\
\hline IGiChPW-wa & 56113,70 & 133 & 1,7 & 2,5 \\
\hline Opole & 439264,00 & 575 & 85,5 & 74,6 \\
\hline Brzozów & 185061,34 & 319 & 51,5 & 55,4 \\
\hline Rzeszów & 54212,06 & 85 & 15,1 & 14,8 \\
\hline Białystok & 182637,40 & 241 & 49,2 & 49,5 \\
\hline Gdańsk & 243513,91 & 552 & 14,4 & 16,7 \\
\hline Gdynia & 234284,58 & 485 & 13,9 & 14,7 \\
\hline Gliwice & 602706,40 & 1027 & 23,0 & 24,0 \\
\hline Kielce & 427854,70 & 1191 & 86,5 & 88,7 \\
\hline Olsztyn & 308721,30 & 525 & 41,0 & 42,9 \\
\hline Poznań & 621465,52 & 1417 & 37,8 & 51,7 \\
\hline Szczecin & 403429,84 & 598 & 43,9 & 40,5 \\
\hline RAZEM & 7997458,47 & 14563 & & \\
\hline
\end{tabular}

Źródło: Dane otrzymane z Centrali Narodowego Funduszu Zdrowia.

Poziom realizacji pakietu onkologicznego przez placówki OZPliCO w poradniach specjalistycznych w poszczególnych województwach waha się między 14,4\% w przypadku Uniwersyteckiego Centrum Klinicznego w Gdańsku a 86,5\% w przypadku Świętokrzyskiego Centrum Onkologii w Kielcach (mediana dla wszystkich placówek w 2017 r. wynosi 37,8\%).

\section{Wnioski}

Z przeprowadzonej analizy danych za okres 1.01 .2015 30.04.2017 wynika, iż realizacja świadczeń z zakresu pakietu onkologicznego w Polsce opiera się głównie na 19 placówkach wchodzących w skład OzPlico. Powyższe wynika z faktu, iż tak niewielka liczba świadczeniodawców (3,5\% wszystkich placówek realizujących pakiet 
onkologiczny w 2017 r.) wykonuje ponad 40\% szybkiej diagnostyki onkologicznej oraz około połowę świadczeń szpitalnych na rzecz pacjentów z kartą DiLO wykonywanych na terenie całego kraju. Biorąc pod uwagę znaczące obciążenie pracą administracyjno-techniczną personelu medycznego oraz konieczność zapewnienia krótkich terminów na diagnostykę i terapię nowotworów, należy stwierdzić, iż członkowie zrzeszeni w OzPlico wzięli na siebie ciężar faktycznej implementacji oraz utrzymania właściwej dostępności do świadczeń onkologicznych dla pacjentów posiadających kartę DiLO.

\section{Oświadczenia}

\section{Oświadczenie dotyczące konfliktu interesów}

Autorzy deklarują brak konfliktu interesów.

\section{Żródła finansowania}

Autorzy deklarują brak źródeł finansowania.

\section{Piśmiennictwo}

1. Ustawa z dnia 22 lipca 2014 r. o zmianie ustawy o świadczeniach opieki zdrowotnej finansowanych ze środków publicznych oraz niektórych innych ustaw, Dz. U. 2014, poz. 1138.

2. Ustawa z dnia 9 marca 2017 r. o zmianie ustawy o świadczeniach opieki zdrowotnej finansowanych ze środków publicznych, Dz. U. 2017 poz. 759

3. Obwieszczenie Ministra Zdrowia z dnia 17 grudnia 2015 r. w sprawie ogłoszenia jednolitego tekstu rozporządzenia Ministra Zdrowia w sprawie świadczeń gwarantowanych z zakresu podstawowej opieki zdrowotnej, Dz. U. 2016 poz. 86.

4. Obwieszczenie Ministra Zdrowia z dnia 25 stycznia 2016 r. w sprawie ogłoszenia jednolitego tekstu rozporządzenia Ministra Zdrowia w sprawie świadczeń gwarantowanych z zakresu ambulatoryjnej opieki specjalistycznej, Dz. U. z 2016 r. poz. 357.

5. Obwieszczenie Ministra Zdrowia z dnia 14 kwietnia 2016 r. w sprawie ogłoszenia jednolitego tekstu rozporządzenia Ministra Zdrowia w sprawie świadczeń gwarantowanych z zakresu leczenia szpitalnego, Dz. U. z 2016 r. poz. 694.

6. Rozporządzenie Ministra Zdrowia z dnia 11 grudnia 2014 r. w sprawie wskaźników rozpoznawania nowotworów, Dz. U. 2014, poz. 1810.

7. Rozporządzenie Ministra Zdrowia z dnia 5 grudnia 2014 r. w sprawie wzoru karty diagnostyki i leczenia onkologicznego, Dz. U. 2014, poz. 1751.

8. Rozporządzenie Ministra Zdrowia z dnia 6 października 2015 r. w sprawie wzoru karty diagnostyki i leczenia onkologicznego. Dz. U. 2015 poz. 1627.
9. Rozporządzenie Ministra Zdrowia z dnia 21 czerwca 2017 r w sprawie wzoru karty diagnostyki i leczenia onkologicznego, Dz. U. 2017 poz. 1250

10. Zarządzenie $\mathrm{Nr} 79 / 2014 / D S O Z$ Prezesa Narodowego Funduszu Zdrowia z dnia 5 grudnia 2014 r. w sprawie określenia warunków zawierania i realizacji umów w rodzaju ambulatoryjna opieka specjalistyczna z późn. zm., dostępne na www.nfz.gov.pl

11. Zarządzenie Nr 62/2016/DSOZ Prezesa Narodowego Funduszu Zdrowia z dnia 29 czerwca 2016 r. w sprawie określenia warunków zawierania i realizacji umów w rodzaju: ambulatoryjna opieka specjalistyczna z późn. zm., dostępne na www. nfz.gov.pl

12. Zarządzenie Nr 80/2014/DGL Prezesa Narodowego Funduszu Zdrowia z dnia 5 grudnia 2014 r. w sprawie określenia warunków zawierania i realizacji umów w rodzaju leczenie szpitalne w zakresie chemioterapia z późn. zm., dostępne na www.nfz.gov.pl

13. Zarządzenie Nr 68/2016/DGL Prezesa Narodowego Funduszu Zdrowia z dnia 30 czerwca 2016 r. w sprawie określenia warunków zawierania i realizacji umów w rodzaju leczenie szpitalne w zakresie chemioterapia z późn. zm., dostępne na www.nfz.gov.pl

14. Zarządzenie Nr 81/2014/DSOZ Prezesa Narodowego Funduszu Zdrowia z dnia 5 grudnia 2014 r. zmieniające zarządzenie w sprawie określenia warunków zawierania i realizacji umów w rodzaju: leczenie szpitalne z późn. zm., dostępne na www.nfz.gov.pl

15. Zarządzenie Nr 89/2013/DSOZ Prezesa Narodowego Funduszu Zdrowia z dnia 19 grudnia 2013 r. w sprawie określenia warunków zawierania i realizacji umów w rodzaju: leczenie szpitalne z późn. zm., dostępne na www.nfz.gov.pl

16. Zarządzenie Nr 71/2016/DSOZ Prezesa Narodowego Funduszu Zdrowia z dnia 30 czerwca 2016 r. w sprawie określenia warunków zawierania i realizacji umów w rodzaju leczenie szpitalne z późn. zm., dostępne na www.nfz.gov.pl

17. http://pakietonkologiczny.gov.pl/

18. https://dilo.nfz.gov.pl/ap-dilo/

19. Chrobot M, Góźdź S, Macek P. Ocena realizacji i wdrażania pakietu onkologicznego w pierwszym półroczu 2015 roku w województwie świętokrzyskim na tle Polski. Polski Przegląd Nauk o Zdrowiu. 2015; 3 (44): 301-306.

Zaakceptowano do edycji: 20.08.19 Zaakceptowano do publikacji: 26.09.19
Adres do korespondencji:
Michał Chrobot
Świętokrzyskie Centrum Onkologii
ul. Artwińskiego 3
25-734 Kielce
tel. +48 533-847-64
faks: 41 / 36-74-705
e-mail: michal.chrobot@onkol.kielce.pl 